\title{
\begin{tabular}{l|l} 
pcori). & PATIENT-CENTERED OUTCOMES RESEARCH INSTITUTE \\
RESEARCH SUMMARY
\end{tabular}
}

\section{Describing How Studies Involve Patients and Healthcare Professionals in Developing Decision Aids and Health- Related Products}

Principal investigator

Organization

Holly Witteman, PhD

Université Laval

\section{What was the project about?}

Patient decision aids help people choose between two or more healthcare options based on what is most important to them. Involving users, such as patients and clinicians, in developing decision aids may make them more useful.

User-centered design is a way to get users involved in creating products. Learning from projects that apply user-centered design may suggest ways to involve users more in developing patient decision aids. In this study, the research team reviewed studies about developing decision aids and studies about usercentered design.

\section{What did the research team do?}

The research team did a systematic review. Systematic reviews combine the results of many studies to summarize what is known on a topic. The team searched for research articles about studies that created decision aids and user-centered design products. Two team members reviewed each article. They looked at how often and in what ways the articles reported that users were involved. The team checked the information with the authors of the articles when needed.

Patients, a caregiver, and clinicians were members of the research team.

\section{What were the results?}

The research team reviewed 579 articles describing 390 studies. Of these, 83 percent were on decision aids. The other 17 percent were on other products for patients, where authors clearly said they applied usercentered design.

The review identified three stages of user-centered design, each having multiple steps. The stages can be repeated. The review looked at how the articles said they involved users at each step.

- Understanding users. Steps included reviewing research and interviewing users. Compared with user-centered design studies, decision aid studies used these steps and involved users less often.

- Developing or refining a product. Steps included adapting a product or developing a draft product. Decision aid and user-centered design studies didn't differ in how often they used this stage. Few studies overall involved users in this stage.

- Watching how people use the product. Decision aid and user-centered design studies didn't differ in how often they involved users in this stage.

Overall, compared with user-centered design studies, decision aid studies asked users their opinions about a product or watched how they used it less often. 


\section{What were the limits of the project?}

Decision aid projects may not have reported all the ways they involved users. Missing information might have changed the study's results.

Future research could explore if and how applying a user-centered design improves the quality of decision aids. Research could also look at ways to engage patients without asking for too much of their time.

\section{How can people use the results?}

People who develop decision aids can use these results when considering ways to involve users.

To learn more about this project, visit www.pcori.org/Witteman277. 